\title{
Acute gastrointestinal haemorrhage on board a cruise ship in the Antarctic Peninsula
}

\author{
Mathieu Carron' ${ }^{1}$, Peter Globokar², Bruno A. Sicard ${ }^{3}$ \\ ${ }^{1}$ Emergency Department, Pasteur 2 Hospital, France \\ ${ }^{2}$ Mooreland Partners, United Kingdom \\ ${ }^{3}$ PMSM, France
}

\begin{abstract}
Antarctic tourism on board cruise ships has expanded since the 1990s, essentially in the Antarctic Peninsula. Due to remoteness, medical cases may evolve into life threatening conditions as emergency medical evacuations are challenging.

We discuss the case of a young crew member who suddenly fainted with an epigastric pain and abundant rectal bleeding while on board a cruise ship heading to the Deception Island $\left(62^{\circ} 57.6\right.$ South, $60^{\circ} 29.5$ West), $44 \mathrm{~h}$ away from Ushuaia by sea. A medical evacuation was necessary to save the patient whose haemog/obin level rapidly decreased from $11 \mathrm{~g} / \mathrm{dL}$ to $8.7 \mathrm{~g} / \mathrm{dL}$ over an $8 \mathrm{~h}$ period due to uncontrolled gastrointestinal bleeding.

Following discussions between the French, Chilean and Argentinean Medical Top Side Support and Maritime Rescue Authorities and despite poor weather conditions, an emergency medical evacuation by air to Chile was made possible. The evacuation, which was 2 days shorter compared to an evacuation by sea, allowed the patient to reach a hospital facility in time to save his life whereas he decompensated in haemorrhagic shock.

As passengers on cruise ships are typically elderly and often following anticoagulant therapies, the risk of bleeding is most important. Facing a gastric haemorrhage, a transfusion is often required. In remote areas, transfusion of fresh whole blood to stabilize a critical patient until he reaches a hospital must be considered.

(Int Marit Health 2016; 67, 4: 223-226)
\end{abstract}

Key words: gastrointestinal haemorrhage, cruise ship, Antarctic, transfusion

\section{INTRODUCTION}

Since the 1990s, Antarctic tourism on board expedition cruise ships has considerably progressed from 6,704 visitors in 1992 to 19,772 in 2004 [1, 2]. Navigation essentially takes place in the Antarctic Peninsula, 2 days away from Ushuaia (Argentina), through the Drake Passage. Only one critical gastrointestinal (gastrointestinal) bleeding case, involving an Antarctic base scientist, was reported [3]. In our paper, we report a life threatening gastrointestinal haemorrhage which occurred while the cruise vessel was navigating in the Antarctic Peninsula and which required a medical evacuation.

\section{CASE REPORT}

On December $6^{\text {th }}, 2014$, our cruise ship, with a capacity of 200 passengers and 139 crew members, was sailing in the Antarctic Peninsula heading to Deception Island at $62^{\circ} 57.6$ South and $60^{\circ} 29.5$ West. At 2:00 AM, a 30-yearold male crew member, native of Mauritius, reached the ship hospital, because of an episode of faintness with brief loss of consciousness. He complained he had been experiencing dizziness and weakness in the previous 3 days. While walking to the examination table, he fainted one more time with a loss of consciousness for less than $30 \mathrm{~s}$. Initial vital signs were not too alarming with blood pressure at $100 / 80 \mathrm{~mm} \mathrm{Hg}$, 
a heart rate at 100 beats/min, a respiratory rate at $18 \mathrm{c} / \mathrm{min}$, a spontaneous oxygen saturation at 99\% and $1.45 \mathrm{~g} / \mathrm{L}$ of glycaemia. The alcohol level in exhaled air was negative. Anaemia was discovered. The initial haemoglobin level was at $11 \mathrm{~g} / \mathrm{dL}$. His past medical history included a peptic ulcer even though his medical certificate did not mention it. The patient mentioned alcohol consumption estimated at 5 beer units every 2 days. No prior intake of over-the-counter, or prescribed drugs was reported. The patient did not display any thoracic pain or any shortness of breath. An epigastric pain had occurred over the previous 3 days, essentially on an empty stomach, partially relieved by food intake. Haemorrhagic stools had been observed, but it did not lead him to consult the ship's medical team at that time. Cardiac, pulmonary and abdominal examinations were normal. Loose stools with blood were found on digital rectal examination. The patient displayed skin paleness with pale conjunctiva. The electrocardiogram showed no abnormalities. Our main hypothesis was a bleeding peptic ulcer.

Initial care at 2:30 AM included an intravenous proton pump inhibitors therapy. The patient's conditions remained stable until 6:30 AM and then deteriorated gradually. The haemoglobin level decreased to $8.7 \mathrm{~g} / \mathrm{dL}$ at 10:15 AM. Another faintness with a loss of consciousness of $30 \mathrm{~s}$ occurred at 8 h 30 accompanied by soft feces. Advice by satellite phone from the Maritime Medical Consultation Centre (MMCC) in Toulouse, France (dedicated medical top side support for French speaking vessels) was obtained and an intravenous treatment with tranexamic acid was started. Because there was no vomiting and doubts existed on the presence of oesophageal varices, no nasogastric tube was inserted. From 10:15 AM until the medical evacuation, which took place at 3:30 PM, the patient remained stable with a heart rate at 120 beats/min and blood pressure at 110/60 mm Hg.

The patient was evacuated with a rigid inflatable boat to the Chilean Frei Station on King Georges Island, South Shetland $\left(60^{\circ} 12.0\right.$ South, $58^{\circ} 57.51$ West). He was conscious. His heart rate was at 140 beats/min and blood pressure at 105/50 mm Hg. A Chilean military land team brought him to an Argentine Military Lockheed C-130 Hercules aircraft which took off at 4:30 PM and reached Rio Gallegos, in Argentina, at 7:00 PM. A 2 L/min nasal oxygen therapy was administered during the flight which was not pressurized. The ship's nurse escorted the patient during the evacuation because there was no physician aboard the flight. She carried an emergency bag with medical protocols in case of acute decompensation.

At the hospital's emergency department, the patient decompensated into a haemorrhagic shock requiring an endotracheal intubation and vasoactive drugs. The haemoglobin level was controlled at $7 \mathrm{~g} / \mathrm{dL}$. The patient was hospitalised in an intensive care unit. An acute bleeding peptic ulcer was confirmed and treated by gastric endoscopy.

\section{OPERATIONAL CHALLENGE OF MEDICAL EVACUATION (FIG. 1-3)}

A medical evacuation from Antarctica to a hospital ashore was necessary to save this patient with life-threatening bleeding. At 2:00 AM, the ship's captain was warned by the ship's physician of the likely need for an evacuation. MMCC was informed at 8:30 AM. The ship's captain, MMCC and the Regional Operational Centre for Surveillance and Rescue (CROSS), Gris-Nez, in France organised the evacuation. The ship was sailing close to Deception Island in Antarctica. For the evacuation, two options were considered: by plane, departing from Frei Station if a runway was available; by sea, crossing the rough sea Drake Passage to Ushuaia for $44 \mathrm{~h}$. The ship sailed heading towards the Chilean Frei Station pending the final evacuation decision

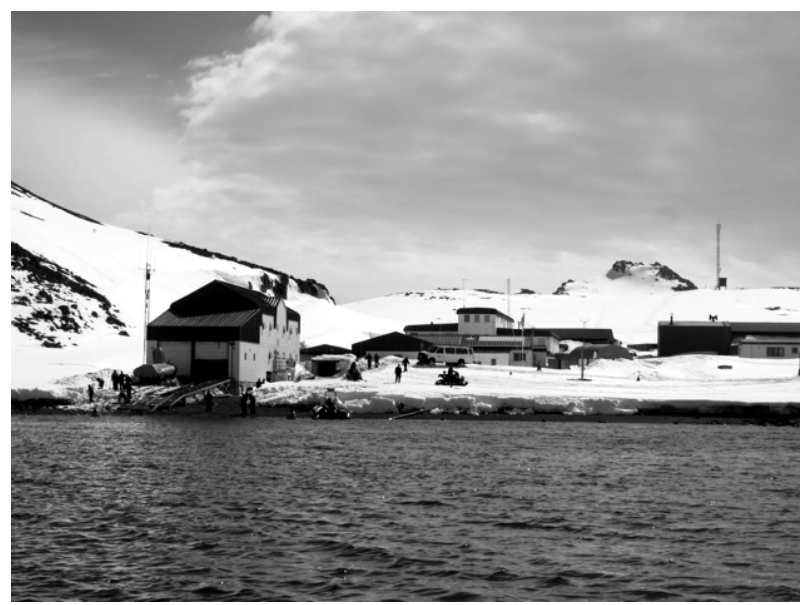

Figure 1. Frei Station, King Georges Island, South Shetland

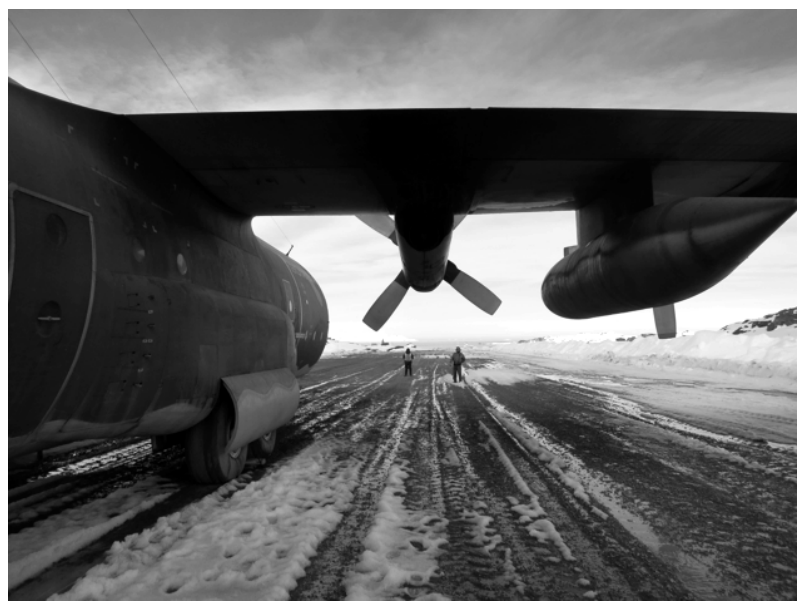

Figure 2. Argentine Military Lockheed $\mathrm{C}-130$ Hercules aircraft positioned on Frei station's runway 


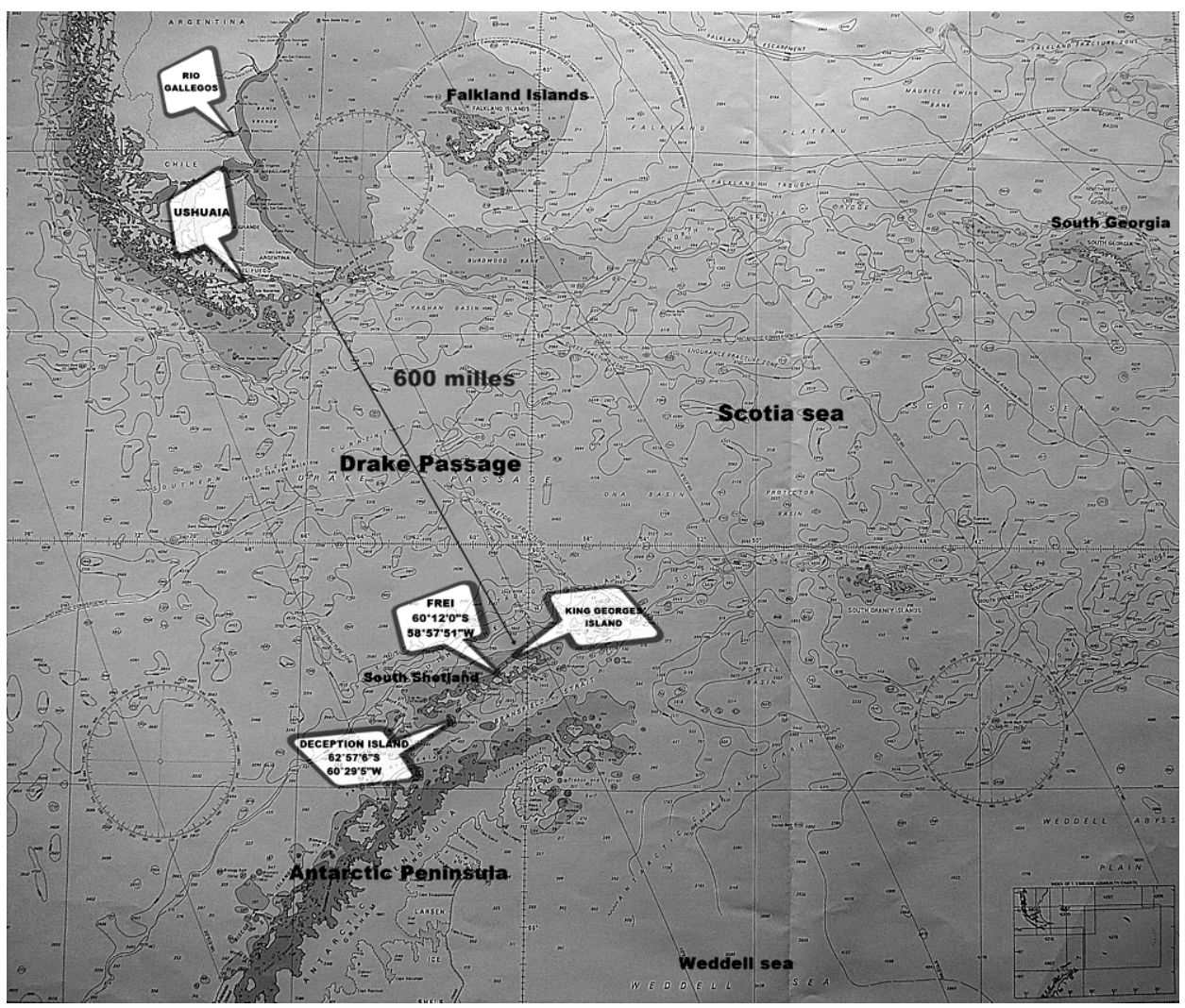

Figure 3. Map of the Scotia Sea

because it was on the way to Ushuaia. Initially, Ushuaia Maritime Rescue Coordination Centre reported the Frei's runway unavailability due to damage. However, at noon the vessel made direct contact with the Chilean Frei station's captain who informed us that an Argentine aircraft was positioned on the runway, cleared for take-off, to evacuate a scientist and that it would wait for the patient. This option, the fastest, was accepted by the rescue staff at 2:40 PM.

\section{DISCUSSION}

In remote areas such as the Antarctic Peninsula, medical cases, even trivial ones, may evolve into life-threatening conditions, without the availability of the full scope of medical tools and expertise. Acute upper gastrointestinal bleeding is among the most common gastrointestinal emergencies with a mortality rate that fluctuates between $5 \%$ and $14 \%$ [4-7]. Even though this condition can stop spontaneously in $80 \%$ of the cases, an emergency gastric endoscopy remains the main therapy when associated with a proton pump inhibitors therapy that decreases the gastric acidity and improves the platelet plug stability [5, 7-9]. Because of the cruise ship's remoteness, an endoscopy would not have been obtainable under $48 \mathrm{~h}$ if we had to sail to Ushuaia. No gastric lavage was done because this therapy had no certain benefit [4]. Because of persistent rectal bleeding, the ship's remoteness and the non-availability of Octreotide acetate (Sandostatin ${ }^{\circledR}$ ), we used tranexamic acid, available on board. This molecule prevents fibrin degradation by the plasmin and stabilises the platelet plug by decreasing the converting plasminogen in plasmin, responsible for fibrinolysis during the blood coagulation [8]. Although tranexamic acid is not recommended in the first instance for upper gastrointestinal bleeding, literature attributes it a decrease of mortality without significantly increasing the thromboembolic risk [10].

In the case of this patient, the management of the medical evacuation was a significant challenge and was only possible at short notice by the coincidental presence of an airplane on a nearby island. In Antarctica, airborne evacuations are difficult and sometimes impossible due to extreme weather conditions. Strong gusty wind, freezing conditions, iced runway limitations, remoteness from the evacuation area make an aerial evacuation uncertain [11]. For a successful operation, international coordination is compulsory [11, 12]. The French cruise ship worked in coordination with the Chilean station Frei, the MMCC of Toulouse, in France, and the international CROSS Gris-Nez in France. The evacuation was carried out by an Argentinian military aircraft, Lockheed C-130 Hercules, which reached an Argentinian hospital in Rio Gallegos and was successful due to perfect international coordination. 
The haemoglobin level of a patient with a gastric haemorrhage decreases progressively and may require a blood transfusion to maintain vital signs. On board cruise ships, the passenger population consists mostly of senior individuals over 65 years, many of whom are following anticoagulant therapies and present a higher risk of bleeding. While the storage of red blood cell pouches on board cruise ships is too complicated mostly due to limited shelf life of blood products, a warm fresh whole blood transfusion should be considered as a necessary and appropriate technique for life threatening bleeding occurrences in remote area. This type of transfusion, already used by civilian and military physicians, permits to stabilise vital signs until the patient reaches a medical centre [13-16]. It requires volunteer donors with perfect matching ABO blood types. A $500 \mathrm{~mL}$ unit of fresh whole blood provides all blood components, including coagulation factors: a haematocrit of $33 \%$ to $43 \% ; 130,000$ to 350,000 platelets per microliter; $86 \%$ activity of clotting factors, stronger than for a whole blood unit [15]. Fresh whole blood does not appear to increase the incidence of transfusion reaction, but it increases transfusion-transmitted infections. A rapid infectious screening test is required to minimize this risk [17].

\section{CONCLUSIONS}

Maritime medicine requires broad medical skills and therapies must be adapted to this environment. Warm fresh whole blood transfusion may stabilise the critically ill patient until a hospital can be reached. Physicians must be trained before embarking and all ship hospitals should have the necessary equipment to do such transfusions.

\section{REFERENCES}

1. Prociv P. Health Aspects of Antarctic tourism. J Travel Med 1998; 5: $210-212$.

2. International Association of Antarctica Tour Operators. Tourism Statistics [01/09/2015]. http://iaato.org/tourism-statistics.

3. Podkolinski MT, Semmens K. Intestinal haemorrhage in Antarctica. A multinational rescue operation. Med J Aust 1979; 2: 275-277.
4. Laine L, Peterson WL. Bleeding peptic ulcer. N Engl J Med 1994; 331: 717-727.

5. Rotondano G. Epidemiology and diagnosis of acute nonvariceal upper gastrointestinal bleeding. Gastroenterol Clin North Am 2014; 43: 643-663.

6. Hearnshaw SA, Logan RF, Lowe D, Travis SP, Murphy MF, Palmer KR. Acute upper gastrointestinal bleeding in the UK: patient characteristics, diagnoses and outcomes in the 2007 UK audit. Gut 2011; 60: 1327-1335.

7. Barkun AN, Bardou M, Kuipers EJ, Sung J, Hunt RH, Martel M, SinclairP. International consensus recommendations on the management of patients with nonvariceal upper gastrointestinal bleeding. Ann Intern Med 2010; 152: 101-113.

8. Bennett C, Klingenberg SL, Langholz E, Gluud LL. Tranexamic acid for upper gastrointestinal bleeding. Cochrane Database Syst Rev. 2014; 11: CD 006640.

9. Masjedizadeh AR, Hajiani E, Alavinejad P, Hashemi SJ, Shayesteh AA, Jamshidian N. High dose versus low dose intravenous pantoprazole in bleeding peptic ulcer : a randomized clinical trial. Middle East J Dig Dis 2014; 6: 137-143.

10. Gluud LL, Klingenberg SL, Langholz SE. Systematic review: tranexamic acid for upper gastrointestinal bleeding. Aliment Pharmacol Ther 2008; 27: 752-758.

11. Mills GH, Mills $\mathrm{CN}$. Challenges of air medical evacuation from Antarctica. Air Med J 2008; 27: 281-285.

12. Mills $\mathrm{CN}$, Mills GH. Mass casualty incident response and aeromedical evacuation in Antarctica. West J Emerg Med 2011; 12: 37-42.

13. Bonnet S, Reslinger V, Malgras B, Pons F, Duverger V. Usefulness of fresh whole blood transfusion in the surgical management of war hemorrhagic shock in the austere environment. E-mémoires de I'Académie Nationale de Chirurgie 2012; 11: 59-65.

14. Cordova CB, Capp AP, Spinella PC. Fresh whole blood transfusion for a combat casualty in austere combat environment. J Spec Oper Med 2014; 14: 9-12.

15. Spinella PC. Warm fresh whole blood transfusion for severe hemorrhage: U.S. military and potential civilian applications. Crit Care Med 2008; 36 (7 Suppl.): S340-S345.

16. Jenkins D, Stubbs J, Williams S, Berns K, Zielinski M, Strandenes G, Zietlow S. Implementation and execution of civilian remote damage control resuscitation programs. Shock 2014; 41 (Suppl. 1): 84-89.

17. Spinella PC, Perkins JG, Grathwohl KW et al. Risks associated with fresh whole blood and red blood cell transfusions in a combat support hospital. Crit Care Med 2007; 35: 2576-2581. 